\title{
Hormone Treatment without Surgery for Patients Aged 75 Years or Older with Operable Breast Cancer
}

\author{
C. J. Wink, MD" ${ }^{1}$, K. Woensdregt, $\mathrm{MD}^{2,3}$, G. A. P. Nieuwenhuijzen, MD, $\mathrm{PhD}^{3}$, M. J. C. van der Sangen, $\mathrm{MD}^{4}$, \\ S. Hutschemaekers, $\mathrm{MD}^{1}$, J. A. Roukema, MD, $\mathrm{PhD}^{5}$, V. C. G. Tjan-Heijnen, MD, $\mathrm{PhD}^{6}$, and A. C. Voogd, $\mathrm{PhD}^{7,8}$ \\ ${ }^{1}$ Faculty of Health Medicine and Life Sciences, Maastricht University, Maastricht, The Netherlands; ${ }^{2}$ Department of \\ Surgery, Maastricht University Medical Center, Maastricht, The Netherlands; ${ }^{3}$ Department of Surgery, Catharina Hospital, \\ Eindhoven, The Netherlands; ${ }^{4}$ Department of Radiotherapy, Catharina Hospital, Eindhoven, The Netherlands; ${ }^{5}$ Department \\ of Surgery, St. Elisabeth Hospital, Tilburg, The Netherlands; ${ }^{6}$ Department of Internal Medicine, Division of Medical \\ Oncology, GROW—School for Oncology and Developmental Biology, Maastricht University Medical Center, Maastricht, \\ The Netherlands; ${ }^{7}$ Department of Epidemiology, Faculty of Health Medicine and Life Sciences, GROW—School for \\ Oncology and Developmental Biology, Maastricht University Medical Center, Maastricht, The Netherlands; ${ }^{8}$ Eindhoven \\ Cancer Registry, Eindhoven, The Netherlands
}

\begin{abstract}
Purpose. To evaluate the trend in the use of primary endocrine treatment (PET) for elderly patients with operable breast cancer and to study mean time to response (TTR), local control, time to progression (TTP), and overall survival.

Methods. Data of 184 patients aged $\geq 75$ years, diagnosed with breast cancer in the south of the Netherlands between 2001 and 2008 and receiving PET, were analyzed.

Results. The percentage of women $\geq 75$ years with breast cancer receiving PET in the south of the Netherlands decreased from $23 \%$ in the period 1988-1992 to $12 \%$ in 1997-2000, and increased to $29 \%$ in 2005-2008. Mean age at diagnosis of 184 patients treated with PET in the period 2001-2008 was 84 years (range 75-89 years). Mean length of follow-up was 2.6 years. In 107 patients (58\%), an initial response was achieved (mean TTR 7 months), 21 patients $(12 \%)$ showed stable disease. A total of 64 patients (35\%), with or without prior response, eventually displayed progression (mean TTP 20 months). No differences in TTR and TTP were observed between the patients starting with tamoxifen or an aromatase inhibitor. One hundred nineteen
\end{abstract}

(C) The Author(s) 2011. This article is published with open access at Springerlink.com

First Received: 3 March 2011;

Published Online: 27 October 2011

C. J. Wink, MD

e-mail: krista_wink@hotmail.com
(65\%) of 184 patients had died by January 1, 2010. In 17 patients (14\%), breast cancer was the cause of death.

Conclusions. Tumor progression was observed in a substantial proportion of the cohort, but only a small number of patients died of breast cancer. Further research is needed on the safety and effectiveness of PET for elderly women with breast cancer to justify the current widespread use.

The optimal treatment of elderly women with breast cancer is difficult to define. Several studies have shown that elderly women with breast cancer are less likely to receive what is considered standard breast cancer treatment compared to their younger counterparts. They are less likely to be treated with surgery and, if treated with surgery, are less likely to undergo breast conserving surgery and axillary lymph node dissection. They are also less likely to receive radiotherapy after breastconserving surgery. ${ }^{1-4}$ Reasons given for the decision to refrain from standard local therapy in elderly breast cancer patients are comorbidity, patient preferences, reduced functional and mental status, and slowly progressive disease requiring less intensive treatment. ${ }^{5-7}$ As an alternative to local therapy, physicians relatively often use tamoxifen or an aromatase inhibitor (AI) as the sole treatment for their elderly patients. ${ }^{5}$ The knowledge that most of the tumors in elderly breast cancer patients are estrogen and/or progesterone receptor positive explains why this primary endocrine therapy (PET) is considered an attractive treatment option. ${ }^{8,9}$

PET has been studied in several randomized controlled trials, all comparing the use of tamoxifen alone to surgery 
with or without adjuvant tamoxifen in older women with breast cancer. In a Cochrane review by Hind et al., based on seven randomized controlled trials involving 1446 elderly women unselected for estrogen receptor status, tamoxifen alone was proven inferior with respect to local control compared to surgery plus endocrine therapy (hazard ratio $0.28,95 \%$ confidence interval [CI] 0.23-0.35). However, no statistically significant difference in overall survival was found when surgery was avoided. ${ }^{10}$ On the basis of the inferior local control rate observed in this review, the use of tamoxifen as PET for elderly patients was discouraged and surgery was recommended, provided that the patient is fit for surgery.

AIs have only been studied in the (neo)adjuvant setting, where they seem to be superior to tamoxifen regarding local tumor response. ${ }^{11-14}$ On the basis of these results, it may be assumed that AIs are also more effective than tamoxifen when used as PET. So far, to our knowledge, no data are available to support this assumption. We think that the number of elderly patients receiving PET has increased since the introduction of AIs. Therefore, the aims of the present study were to analyze the trend in the use of PET in elderly breast cancer patients in the southeast of the Netherlands over the last decade and to compare the local control rates between users of AIs and tamoxifen.

\section{METHODS}

\section{Patients}

Trends in the use of PET were studied by using data from the Eindhoven Cancer Registry (ECR), which is a population-based registry serving a population of approximately 2.4 million inhabitants in the southern part of the Netherlands. Data were used from all patients aged 75 years or older who were diagnosed with breast cancer during 1988-2008. To collect additional information from clinical records, 223 breast cancer patients aged 75 years or older were selected who were treated with PET in 4 of the 10 hospitals covered by the ECR in the period 2001-2008. These hospitals were selected because of their vicinity to the hospital of the principal investigator (C.J.W.), thus facilitating data collection. These 223 patients represent $40 \%$ of all patients treated with PET in the ECR region in that period. The clinical records of all 223 patients were reviewed to collect detailed information regarding clinical stage at diagnosis, histopathology of the tumor, hormone receptor status, reason or reasons for choosing PET instead of surgery, local tumor response, local progression of disease, and date and cause of death. Family physicians and nursing home physicians were contacted, if possible, in case of missing follow-up data. January 1, 2010, was considered the end of the follow-up period. After examination of the clinical records, 39 patients were excluded: 34 patients had metastatic disease at diagnosis, two patients had already been receiving endocrine therapy before a histological diagnosis of breast cancer was made, one patient was male, one patient had also received chemotherapy within a week after initiating PET, and one patient had received radiofrequency ablation before the start of PET. After exclusion of these patients, 184 patients remained available for the analyses.

\section{Statistical Analyses}

Trends in the use of PET in the period 1988-2008 were studied by calculating the proportion of all patients with breast cancer receiving PET for all separate years of diagnosis and statistical significance was tested by the Mantel-Haenszel Chi-square test.

For the selected cohort of 184 patients we collected information on their local tumor response to PET (initial decrease of tumor size, stable disease, and local progression), as confirmed by physical examination or breast imaging. We calculated the time to complete or partial local response (TTR) or time to progression (TTP) after PET. Information was also collected on the date and cause of death. Time until these end points was calculated from the date of start of PET. Survival was calculated from the time of diagnosis until death or January 1, 2010. A KaplanMeier analysis with a log rank test was used to calculate overall and 5-year survival. Survival of the 184 patients receiving $\mathrm{PET}$, with or without delayed surgery, in the period 2001-2008 was compared with the survival of all patients aged 75 years or older who received primary surgery in the south of the Netherlands in the same period $(n=1504)$.

\section{RESULTS}

\section{Trends in the Use of PET}

During 1988-2008, a total of 4650 patients $\geq 75$ years were diagnosed with breast cancer in the south of the Netherlands. Of these, $3510(75.5 \%)$ received surgery as primary treatment, and $946(20.3 \%)$ were treated with PET. When analyzing the use of PET over the years, a biphasic trend was observed (Fig. 1). Between 1988 and 1992, 23\% of the women 75 years or older in the southeast of the Netherlands received PET. This percentage decreased to $12 \%$ in the period $1997-2000(P<0.001)$, followed by an increase to $29 \%$ in the period $2005-2008(P=0.001)$. The percentage of elderly breast cancer patients treated with PET varied from $9 \%$ to $44 \%$ between hospitals between 


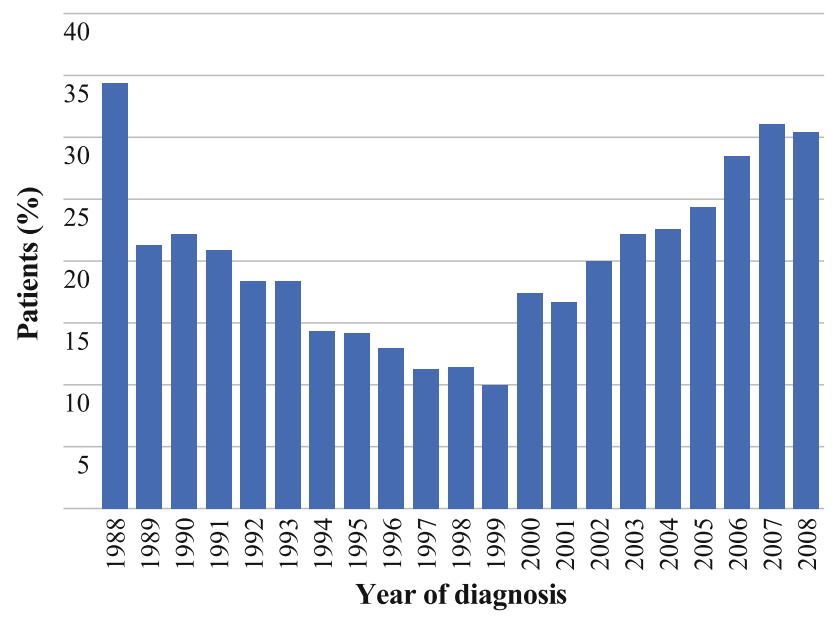

FIG. 1 Percentage of patients aged $\geq 75$ years with breast cancer receiving primary endocrine treatment in the south of the Netherlands in the period $1988-2008$ by year of diagnosis

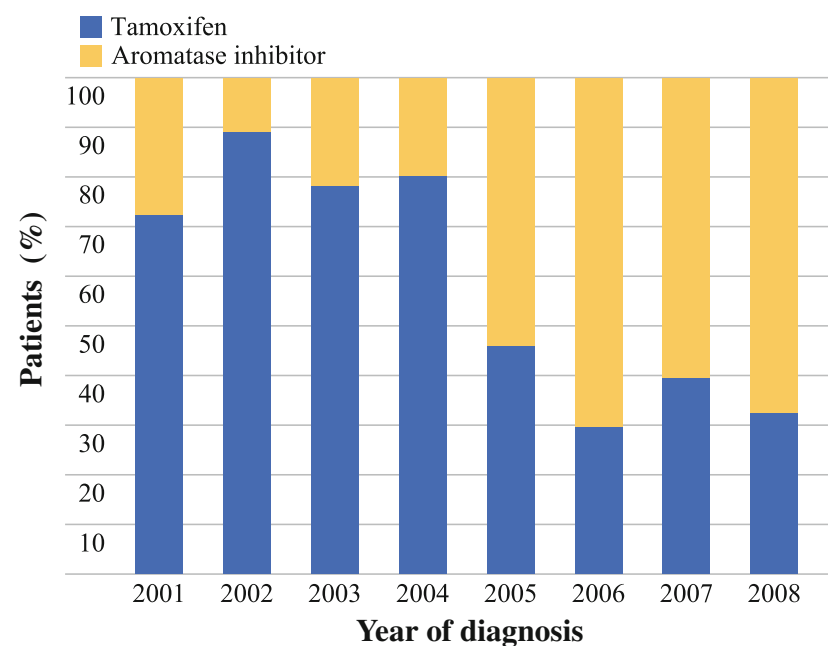

FIG. 2 Type of endocrine treatment for the studied cohort of 184 patients $\geq 75$ years with breast cancer treated with primary endocrine treatment in the south of the Netherlands in the period 2001-2008 by year of diagnosis

1988 and 2008. The prescribed type of PET varied over the years. In the studied cohort, most patients received tamoxifen until 2004. From 2005 onward, AIs were prescribed to $60-70 \%$ of the patients receiving PET (Fig. 2).

\section{Patient Characteristics}

Details of the 184 patients of whom the clinical records were examined are presented in Table 1 . The mean age at diagnosis of the primary tumor was 84 years (range 75-89 years). Most tumors were invasive ductal carcinomas $(n=115,63 \%)$. Hormone receptor status was not known for $16.3 \%$ of the patients, either because patients refused a histological biopsy, or because only a fine-needle biopsy was performed or insufficient material was obtained
TABLE 1 Characteristics of 184 patients aged $\geq 75$ years who received PET in the south of the Netherlands between 2001 and 2008

\begin{tabular}{|c|c|c|}
\hline Characteristic & $n$ & $\%$ \\
\hline \multicolumn{3}{|l|}{ Clinical tumor status (cT) } \\
\hline 1 & 55 & 29.8 \\
\hline 2 & 94 & 51.1 \\
\hline 3 & 3 & 1.6 \\
\hline 4 & 27 & 14.7 \\
\hline Unknown & 5 & 2.7 \\
\hline \multicolumn{3}{|l|}{ Clinical nodal status $(\mathrm{cN})$} \\
\hline Positive & 41 & 22.3 \\
\hline Negative & 129 & 70.1 \\
\hline Unknown & 14 & 7.6 \\
\hline \multicolumn{3}{|c|}{ Histological type of primary tumor ${ }^{\mathrm{a}}$} \\
\hline Invasive ductal & 115 & 62.5 \\
\hline Invasive lobular & 27 & 14.7 \\
\hline Other & 7 & 3.8 \\
\hline Unknown & 35 & 19.0 \\
\hline \multicolumn{3}{|l|}{ Estrogen receptor status ${ }^{\mathrm{a}}$} \\
\hline Positive & 145 & 78.8 \\
\hline Negative & 9 & 4.9 \\
\hline Unknown & 30 & 16.3 \\
\hline \multicolumn{3}{|l|}{ Progesterone receptor status ${ }^{\mathrm{a}}$} \\
\hline Positive & 117 & 63.6 \\
\hline Negative & 37 & 20.1 \\
\hline Unknown & 30 & 16.3 \\
\hline \multicolumn{3}{|l|}{ HER2 status $^{\mathrm{a}}$} \\
\hline Positive & 4 & 2.2 \\
\hline Negative & 66 & 35.9 \\
\hline Unknown & 114 & 62.0 \\
\hline \multicolumn{3}{|l|}{ No. of comorbidities } \\
\hline 0 & 16 & 8.7 \\
\hline 1 & 51 & 27.7 \\
\hline 2 & 41 & 22.3 \\
\hline 3 & 42 & 22.8 \\
\hline$\geq 4$ & 24 & 13.0 \\
\hline \multicolumn{3}{|l|}{ First-line endocrine agent } \\
\hline Tamoxifen & 101 & 54.9 \\
\hline AI & 82 & 44.6 \\
\hline Letrozole (Femara) & 30 & 16.3 \\
\hline Anastrozole (Arimidex) & 39 & 21.2 \\
\hline Exemestane (Aromasin) & 13 & 7.1 \\
\hline Unknown & 1 & 0.5 \\
\hline
\end{tabular}

${ }^{a}$ Information derived from fine-needle aspiration biopsy

by large-core needle biopsy. Nine patients (5\%) with a negative hormone receptor status (defined as a receptor positivity of less than $10 \%$ ) received PET.

One hundred one patients $(55 \%)$ were treated with tamoxifen as the initial therapy, 82 patients initiated 
therapy with an AI (45\%), and for one patient, the type of endocrine therapy was not known. Several reasons to prescribe PET instead of performing surgery were mentioned in the clinical records. In 65 patients, the treating physician declared the presence of comorbidities to be a reason for omitting surgery, and in 27 patients, age was considered to be an important reason to opt for PET. Seventy-six patients were reported to have chosen PET over surgery themselves.

\section{Response and TTP}

In 107 patients (58\%), an initial response (partial regression or complete clinical response of the primary tumor) was observed at physical examination by the responsible physician. In $62(58 \%)$ of these 107 patients, this local response was confirmed by breast imaging (mammogram or breast ultrasound). The average \pm standard deviation time to response (TTR) after initiating PET was $7 \pm 5$ months. In 21 patients $(11 \%)$, the tumor remained locally stable after initiating PET (no regression or progression). Twenty-four patients (13\%) had local disease progression without an initial local response, and $40(37 \%)$ of the 107 patients with an initial response to the PET eventually showed local progression. Thus, a total of 64 patients (35\%) eventually experienced local progression of their disease despite endocrine therapy. The average \pm standard deviation TTP after starting PET was $20 \pm 17$ months). In 38 patients, the local progression resulted in a switch to another hormone therapy, and 7 patients received rescue surgery. Two patients received no other treatment, 2 had radiofrequency ablation, 1 had chemotherapy, 6 continued to receive endocrine treatment until their death, and 4 patients were still receiving endocrine treatment by the end of the follow-up period. For 4 patients, information on treatment after local progression was not available. Eventually, 8 of the 38 patients who switched to another hormone therapy after local tumor progression also needed to undergo surgery. Other reasons to switch or stop the initial treatment, besides progression of disease, were adverse effects of PET, lack of tumor regression, or to prevent progression after a certain time. By the end of the follow-up period, 22 (12\%) of 184 patients had undergone surgery, and 54 patients (29\%) had switched to another hormone agent. Of the 22 patients who started with PET and eventually underwent surgery, 6 developed a local recurrence after surgery.

\section{Tamoxifen versus AIs}

The mean length of follow-up was 3.0 years for patients who received tamoxifen, versus 2.2 years for the patients receiving an AI $(P=0.006)$. The Kaplan-Meier analysis

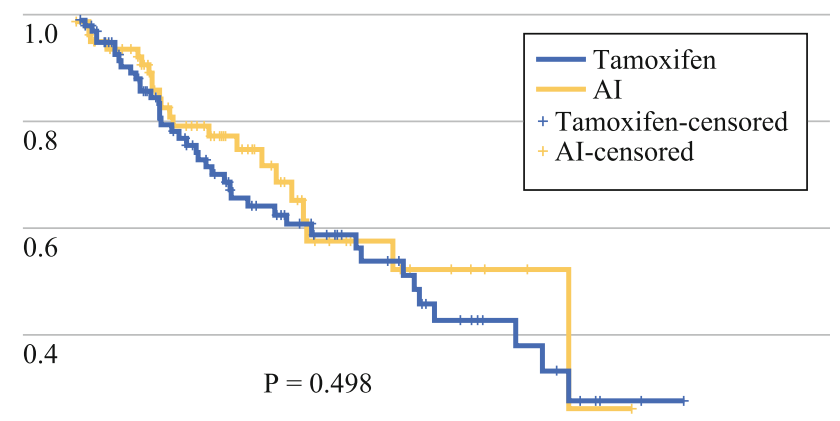

0.2

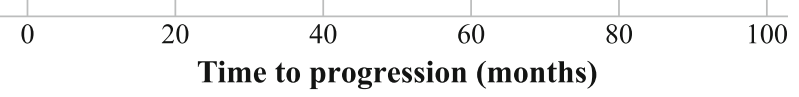

FIG. 3 TTP of 184 patients aged $\geq 75$ years who received primary endocrine treatment in the period 2001-2008 in the south of the Netherlands: tamoxifen compared to aromatase inhibitors (AIs)

revealed no significant difference in TTR $(P=0.487)$ or TTP between both groups $(P=0.498$; Fig. 3$)$.

Survival

The mean length of follow-up from diagnosis for all 184 patients was 2.6 years (range $0.08-8.48$ years). By the end of the follow-up period, 119 patients $(65 \%)$ had died. In 17 of these patients (14\%), breast cancer was the cause of death. For 32 patients the cause of death could not be retrieved and 70 patients (59\%) died of non-breast-cancerrelated causes.

The 5-year overall survival of the patients receiving PET was $27 \%$ (95\% CI 19.1-34.8), versus $62.3 \%(95 \%$ CI

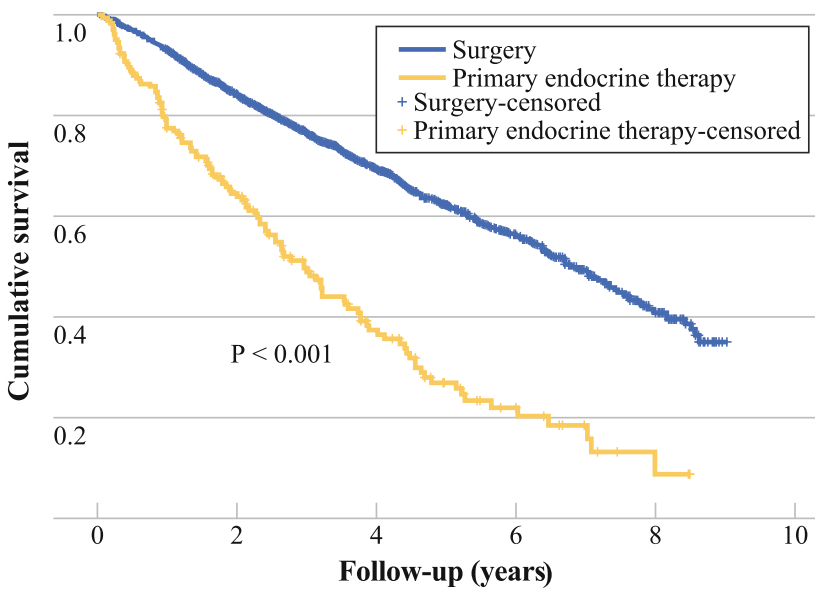

FIG. 4 Overall survival of 184 patients aged $\geq 75$ years who received primary endocrine treatment in the period 2001-2008 in the south of the Netherlands vs. all patients aged $\geq 75$ years treated with primary surgery in the same region and time period $(n=1504)$ 
TABLE 2 Age and comorbidity of patients aged $\geq 75$ years who received surgery or PET for breast cancer in the south of the Netherlands between 2001 and 2008

\begin{tabular}{|c|c|c|c|c|c|}
\hline \multirow[t]{3}{*}{ Characteristic } & \multicolumn{4}{|c|}{ Treatment } & \multirow[t]{3}{*}{$P$ value } \\
\hline & \multicolumn{2}{|c|}{ Surgery $(n=1504)$} & \multicolumn{2}{|c|}{$\operatorname{PET}(n=184)$} & \\
\hline & $n$ & $\%$ & $n$ & $\%$ & \\
\hline Mean age, y & 80.2 & & 83.8 & & $<0.001$ \\
\hline No. of comorbidities & & & & & $<0.001$ \\
\hline 0 & 325 & 21.6 & 16 & 8.7 & \\
\hline 1 & 448 & 29.8 & 51 & 27.7 & \\
\hline$\geq 2$ & 574 & 38.2 & 107 & 58.2 & \\
\hline Unknown & 157 & 10.4 & 10 & 5.4 & \\
\hline
\end{tabular}

59.4-65.2) for the breast cancer patients $\geq 75$ years in the south of the Netherlands treated primarily with surgery (with or without adjuvant treatment) during the same period (Fig. 4). Age and prevalence of comorbidity differed significantly between the two groups: the patients treated with surgery were younger and had significantly less comorbidities (Table 2).

\section{DISCUSSION}

Our analysis of data retrieved from the ECR showed a biphasic trend in the use of PET in the south of the Netherlands over the last two decades, with an initial decrease followed by a sharp increase again after 1999 . This is a remarkable finding, considering the described inferiority of tamoxifen compared to surgery with regard to local control and the lack of evidence-based data concerning local control and survival with monotherapy with $\mathrm{AI}$ in the literature. We cannot give a definitive explanation for this trend, but we hypothesize that the initial downward trend may be the effect of the growing evidence for the inferiority of tamoxifen compared to surgery with respect to local control appearing between 1988 and $1998 .^{15-18}$ This may have caused physicians to be hesitant to prescribe PET, out of fear for the development of irresectable local disease. The arrival of the AIs, with good clinical results in the (neo)adjuvant setting, may have reduced this fear and could explain the rise in the use of endocrine therapy as primary treatment for elderly breast cancer patients from 2000 onward. ${ }^{11-14}$ This hypothesis is supported by our finding that the use of AIs, compared to tamoxifen, has increased over the last couple of years (Fig. 2). To date, no successful research on the effectiveness and safety of monotherapy with AIs has been performed in elderly women with breast cancer. Several studies have failed-for example, the ESTEeM (Endocrine + Surgical Therapy for Elderly women with Mammary cancer) trial.
This multicenter randomized trial in the UK planned to compare surgery with adjuvant anastrozole versus primary anastrozole in 1200 women aged $\geq 75$ years with estrogen receptor-positive, early operable primary breast cancer. Unfortunately, unsatisfactory recruitment caused the trial to be closed prematurely. ${ }^{19}$

Not only in the south of the Netherlands but also in other parts of Europe, a substantial number of elderly women with breast cancer are receiving PET. ${ }^{5,20}$ Wyld et al. reported $40 \%$ of the women $\geq 70$ years were receiving PET for breast cancer in the UK in 2002. ${ }^{5}$ We found large differences between hospitals in the percentage of elderly breast cancer patients treated with PET in the south of the Netherlands, indicating that there is a lack of consensus between physicians with respect to its use. Such lack of consensus is also apparent in the UK, where data from the Breast Cancer Clinical Outcome Measures Report showed that nonsurgical treatment rates vary $11-40 \%$ between hospitals in women aged $\geq 70$ years. ${ }^{21}$ The widespread use of PET, the large variation in prescription rates between hospitals, and the lack of evidence for the safety and effectiveness emphasize the need for randomized studies on AI, or PET in general, among elderly women. Survival in our cohort was significantly compromised, as compared to the group primarily treated with surgery $(P<0.001)$. This result is difficult to interpret because of the nonrandomized study design. At least it indicates that PET was generally reserved for patients in poor physical condition, as was expressed by the large difference in age and comorbidity between the two groups. Comorbidity was also mentioned in the medical files as an important reason to choose PET instead of surgery. This finding on the role of comorbidity is consistent with previous studies addressing the influence of comorbidity on treatment decisions and survival for elderly patients with breast cancer. For example, Louwman et al. described that patients aged 80 years or older were less often treated with optimal surgery alone in the presence of comorbidity ( $21 \%$ vs. $26 \%$, $P=0.09)$ and more often treated with tamoxifen only (21\% vs. $14 \%, P=0.01) .^{22}$ Satariano et al. observed an overall association between comorbidity and type of breast cancer treatment $(P<0.001) .^{23}$

The meta-analysis by Hind et al. showed no difference in overall survival between women treated with tamoxifen only and women treated with surgery with or without adjuvant tamoxifen. ${ }^{10}$ Only one of the included randomized controlled trials showed an advantage in survival for surgery with adjuvant endocrine therapy. In a randomized trial by Fennessy et al., an overall 5-year survival of $67 \%$ was observed after surgery with adjuvant tamoxifen versus $59.5 \%$ after tamoxifen only. ${ }^{24}$

Because of the retrospective design of our study, quality of life was not assessed. Given the limited life expectancy of these older patients, quality of life may be at least as 
important as the potential survival gain associated with the different treatment options. Several other limitations also relate to the retrospective study design, such as residual confounding when comparing the results of the different treatment options. Performance status, social support, and therapy compliance are examples of potential sources of such residual confounding, especially in the elderly.

The gathering of long-term follow-up information of elderly patients was challenging for several reasons. Medical files of some patients who had died had already been destroyed, and in some of these cases, information could not be obtained from their family physicians. Moreover, not all family physicians or nursing home physicians could be reached, and some of them refused to participate. This may have caused an underestimation of the number of patients with disease progression. Because this was a retrospective study, patients were not evaluated at set times during their treatment. Therefore, it is possible that initial treatment responses had been missed and only progression was recorded properly in the medical file. Survival data were obtained from the cancer registry and were complete. However, the cause of death remained uncertain for 32 patients (17.4\%). We cannot think of any reason why the distribution of the causes of death for these patients would have been different than for the patients for whom the cause of death was known.

In conclusion, survival in our group of patients treated with PET was compromised compared to the patients $\geq 75$ years treated with primary surgery in the same period. This was probably due to differences in age and comorbidity at baseline, causing the physicians to choose a different treatment modality. The fact that most of the patients in our group died of other causes than breast cancer supports those treatment choices. However, the definite role of PET in the management of breast cancer in the elderly needs to be further assessed. There is still a lack of evidence to justify the current widespread use of PET as primary therapy for elderly women with breast cancer. PET for breast cancer should be limited to the frail older patient who is unfit for surgery. Further research is needed, particularly in the areas of improved identification of the frail patient and the safety, quality of life, and effectiveness of monotherapy with AIs.

OPEN ACCESS This article is distributed under the terms of the Creative Commons Attribution Noncommercial License which permits any noncommercial use, distribution, and reproduction in any medium, provided the original author(s) and source are credited.

\section{REFERENCES}

1. Bergman L, Kluck HM, van Leeuwen FE, et al. The influence of age on treatment choice and survival of elderly breast cancer patients in south-eastern Netherlands: a population-based study. Eur J Cancer. 1992;28A(8-9):1475-80.

2. Giordano SH, Hortobagyi GN, Kau SW, Theriault RL, Bondy ML. Breast cancer treatment guidelines in older women. J Clin Oncol. 2005;23:783-91.

3. Bouchardy C, Rapiti E, Fioretta G, et al. Undertreatment strongly decreases prognosis of breast cancer in elderly women. $J$ Clin Oncol. 2003;21:3580-7.

4. Lavelle K, Todd C, Moran A, Howell A, Bundred N, Campbell M. Non-standard management of breast cancer increases with age in the UK: a population based cohort of women $>$ or $=65$ years. Br J Cancer. 2007;96:1197-203.

5. Wyld L, Garg DK, Kumar ID, Brown H, Reed MW. Stage and treatment variation with age in postmenopausal women with breast cancer: compliance with guidelines. Br J Cancer. 2004;90: 1486-91.

6. Velanovich V, Gabel M, Walker EM, et al. Causes for the undertreatment of elderly breast cancer patients: tailoring treatments to individual patients. J Am Coll Surg. 2002;194:8-13.

7. Hooper SB, Hill AD, Kennedy S, et al. Tamoxifen as the primary treatment in elderly patients with breast cancer. Ir J Med Sci. 2002;171:28-30.

8. Diab SG, Elledge RM, Clark GM. Tumor characteristics and clinical outcome of elderly women with breast cancer. J Natl Cancer Inst. 2000;92:550-6.

9. McCarty KS Jr, Silva JS, Cox EB, Leight GS Jr, Wells SA Jr, McCarty KS Sr. Relationship of age and menopausal status to estrogen receptor content in primary carcinoma of the breast. Ann Surg. 1983;197:123-7.

10. Hind D, Wyld L, Reed MW. Surgery, with or without tamoxifen, vs tamoxifen alone for older women with operable breast cancer: Cochrane review. Br J Cancer. 2007;96:1025-9.

11. Seo JH, Kim YH, Kim JS. Meta-analysis of pre-operative aromatase inhibitor versus tamoxifen in postmenopausal woman with hormone receptor-positive breast cancer. Cancer Chemother Pharmacol. 2009;63:261-6.

12. Mathew J, Asgeirsson KS, Jackson LR, Cheung KL, Robertson JF. Neoadjuvant endocrine treatment in primary breast cancerreview of literature. Breast. 2009;18:339-44.

13. Dowsett M, Cuzick J, Ingle J, et al. Meta-analysis of breast cancer outcomes in adjuvant trials of aromatase inhibitors versus tamoxifen. J Clin Oncol. 2010;28:509-18.

14. Eiermann W, Paepke S, Appfelstaedt J, et al. Preoperative treatment of postmenopausal breast cancer patients with letrozole: a randomized double-blind multicenter study. Ann Oncol. 2001;12:1527-32.

15. Bates T, Riley DL, Houghton J, Fallowfield L, Baum M. Breast cancer in elderly women: a Cancer Research Campaign trial comparing treatment with tamoxifen and optimal surgery with tamoxifen alone. The Elderly Breast Cancer Working Party. Br J Surg. 1991;78:591-4.

16. Kenny FS, Robertson JFR, Ellis IO, Elston CW, Blarney RW. Long-term follow-up of elderly patients randomized to primary tamoxifen or wedge mastectomy as initial therapy for operable breast cancer. Breast. 1998;7:335-9.

17. Willsher PC, Robertson JFR, Jackson L, Al-Hilaly M, Blarney $\mathrm{RW}$. Investigation of primary tamoxifen therapy for elderly patients with operable breast cancer. Breast. 1997;6:150-4.

18. Robertson JF, Todd JH, Ellis IO, Elston CW, Blamey RW. Comparison of mastectomy with tamoxifen for treating elderly patients with operable breast cancer. BMJ. 1988;297(6647):511-4.

19. Chakrabarti J, Kenny FS, Syed BM, Robertson JF, Blamey RW, Cheung KL. A randomised trial of mastectomy only versus tamoxifen for treating elderly patients with operable primary breast cancer-final results at 20-year follow-up. Crit Rev Oncol Hematol. 2011;78:260-4. 
20. Syed BM, Al-Khyatt W, Johnston SJ, et al. Long-term clinical outcome of oestrogen receptor positive operable primary breast cancer in older women: a large series from a single centre. $\mathrm{Br} J$ Cancer. 2011;104:1393-400.

21. Breast Cancer Clinical Outcome Measures Project. (BCCOM). Analysis of the management of symptomatic breast cancers diagnosed in 2004, 3rd year report. 2007. www.baso.org.uk/ Downloads/BCCOM_AR09.pdf.

22. Louwman WJ, Janssen-Heijnen ML, Houterman S, et al. Less extensive treatment and inferior prognosis for breast cancer patient with comorbidity: a population-based study. Eur J Cancer. 2005;41:779-85.

23. Satariano WA, Ragland DR. The effect of comorbidity on 3-year survival of women with primary breast cancer. Ann Intern Med. 1994;120:104-10.

24. Fennessy M, Bates T, MacRae K, Riley D, Houghton J, Baum M. Late follow-up of a randomized trial of surgery plus tamoxifen versus tamoxifen alone in women aged over 70 years with operable breast cancer. Br J Surg. 2004;91:699-704. 